\title{
MODIFIKASI VANILIN DENGAN ASAM p-HIDROKSI BENZOAT DAN UJ AKTIVITASNYA TERHADAP Pseudomonas aeruginosa, Staphylococcus aureus DAN Candida albicans
}

\section{CHEMICAL STRUCTURE MODIFICATION OF VANILLIN WITH PARAHYDROXYBENZOIC ACID AND ITS ANTIMICROBIAL ACTIVITY AGAINST Pseudomonas aeruginosa, Staphylococcus aureus, AND Candida albicans}

\author{
Faridlatul Hasanah, Adia Putra Wirman
}

Fakultas Farmasi dan Sains, Universitas Muhammadiyah Prof. Dr. Hamka Klender, Jalan Delima II/IV, RT.9/RW.3, Malaka Sari, Duren Sawit, Kota Jakarta Timur, Daerah Khusus Ibukota Jakarta 13460, Indonesia Email: faridlahasanah@gmail.com (Faridlatul Hasanah)

\begin{abstract}
ABSTRAK
Penemuan senyawa antimikroba baru merupakan hal yang menarik untuk terus dikembangan, hal ini disebabkan meningkatnya resistensi antimikroba secara global. Penelitian ini bertujuan untuk mensintesis senyawa baru yaitu vanilil para hidroksibenzoat (vanilil p-hidroksibenzoat) yang diharapkan memiliki aktivitas antimikroba. Penelitian diawali dengan mensintesis vanilil $\mathrm{p}$-hidroksibenzoat melalui reaksi reduksi dan esterifikasi. Senyawa vanillin direduksi terlebih dahulu menjadi vanilil alkohol untuk meminimalisasi halangan sterik pada reaksi esterifikasi. Senyawa hasil reduksi dilanjutkan reaksi esterifikasi menggunakan metode Steglich dengan asam para hidroksibenzoat. Senyawa yang dihasilkan dianalisis dengan menggunakan Kromatografi Lapis Tipis (KLT), Fourier-Transform Infrared Spectroscopy (FTIR), spektroskopi MS, dan spektroskopi NMR. Senyawa ester yang terbentuk mempunyai titik leleh dari yaitu 152$154{ }^{\circ} \mathrm{C}$ dengan rendemen $55,90 \%$. Hasil elusidasi struktur dengan FTIR dan spektrum ${ }^{1} \mathrm{H}$ NMR menunjukkan kesesuaian dengan senyawa yang diinginkan yaitu vanilil $p$ hidroksibenzoat. Daya antimikroba senyawa vanilil p-hidroksibenzoat terhadap bakteri Staphylococcus aureus pada konsentrasi 200 dan 400 ppm termasuk kategori lemah. Sedangkan pada konsentrasi 600 ppm dikategorikan sedang. Uji aktivitas terhadap Pseudomonas aeroginosa pada konsentrasi 200 dan 400 ppm termasuk kategori sedang dan pada konsentrasi 600 ppm dikategorikan kuat. Senyawa hasil sintesis tidak memiliki aktivitas sebagai antijamur.
\end{abstract}

Kata kunci: antimikroba, metode Steglich, vanilil p-hidroksibenzoat. 


\begin{abstract}
New antimicrobial discovery is an interesting field of study, related to the increase of the occurrence of antibiotic resistance globally. This research aimed to synthesize a new vanillyl $p$-hydroxybenzoate that might possess antimicrobial properties. The synthesis of vanillyl p-hydroxybenzoate was conducted through reduction and esterification. Vanillin was reduced to vanillyl alcohol to minimize steric hindrance during esterification reaction. The compound resulted from reduction reaction was further reacted in esterification with Steglich method using p-hydroxybenzoic acid. The obtained was further analyzed with Thin Layer Chromatography (TLC), Fourier Transform Infrared Spectroscopy (FTIR), Mass spectroscopy (MS), and Nuclear Magnetic Resonance (NMR) Spectroscopy. The ester resulted from this study had a melting point of $152-154{ }^{\circ} \mathrm{C}$, with a total yield of $55.90 \%$. The FTIR and ${ }^{1} \mathrm{H}-\mathrm{NMR}$ spectra of the ester demonstrated similarities with those of vanillyl $p$-hydroxybenzoate. The antimicrobial activity of this compound against Staphylococcus aureus at concentrations of 200 and 400 ppm was weak, while that at a concentration of $600 \mathrm{ppm}$ was considered moderate. When it was tested against Pseudomonas aeruginosa, it showed a moderate activity at concentrations of 200 and 400 ppm, and a strong activity at a concentration of 600 ppm. However, the product of this synthesis did not show antifungal activities.
\end{abstract}

Key words: antimicrobial, Steglich methods, vanillyl p-hydroxybenzoate. 


\section{Pendahuluan}

Peningkatan

resistensi

antimikroba merupakan krisis global yang harus segera diatasi (WHO, 2016). Salah satu cara untuk mengatasinya adalah dengan menemukan antimikroba baru dengan struktur yang berbeda dengan antimikroba yang beredar. Vanilin merupakan senyawa yang aktif sebagai antimikroba dan sangat berpotensi untuk dikembangkan dalam pengobatan.

Vanilin

(4-hidroksi-3-

metoksibenzaldehida) merupakan kristal berwarna putih atau putih kekuningan yang banyak digunakan sebagai pewangi makanan. Vanilin dihasilkan dari buah panili (Vanilla fragrans). Tanaman panili dapat tumbuh dengan baik di kawasan tropis, salah satunya di Indonesia.

Vanilin merupakan senyawa aldehida aromatik dengan rumus molekul $\mathrm{C}_{8} \mathrm{H}_{8} \mathrm{O}_{3}$. Dilihat dari struktur kimianya, vanilin merupakan senyawa fenol tersubstitusi gugus metoksi pada posisi orto dan gugus aldehida pada posisi para, sehingga vanilin dapat dikelompokkan sebagai senyawa antioksidan dan juga mempunyai aktivitas antibakteri (Fitzgerald et al., 2004). Apabila vanilin dikenai reaksi reduksi akan diperoleh senyawa vanilil alkohol.

Vanilil alkohol juga merupakan senyawa fenolik, sehingga memiliki potensi sebagai antioksidan. Senyawa vanilin biasa digunakan sebagai zat pengaroma pada makanan dan sediaan farmasi. Beberapa riset menunjukkan bahwa turunan vanillin memiliki beberapa aktivitas, antara lain aktivitas antimikroba (Kumar et al., 2012). antijamur (Boonchird and Flegel, 1982) dan antioksidan (Oliveira et al., 2014). Aktivitas antimikroba turunan vanilin meliputi gram positif dan negatif (Rakchoy et al., 2009), dalam penelitian ini mikroorganisme uji yang digunakan adalah Staphylococcus aureus, Pseudomonas aeroginosa, dan Candida albicans.

Winarto (2013) telah berhasil mensintesis turunan vanilin yaitu vanilil sinamat dari vanilil alkohol. Reaksi esterifikasi dipengaruhi beberapa faktor, salah satunya halangan atom sterik. Senyawa vanilin direduksi terlebih dahulu menjadi vanilil alkohol untuk meminimalisasi gangguan halangan sterik pada reaksi esterifikasi.

Reaksi esterifikasi yaitu reaksi langsung antara asam karboksilat dengan alkohol menghasilkan senyawa 
ester. Pada dasarnya reaksi esterifikasi memiliki energi aktivitasi yang tinggi dan membutuhkan waktu yang lama untuk mencapai kesetimbangannya. Katalis merupakan zat lain selain reaktan dan produk, yang ditambahkan pada suatu sistem reaksi untuk meningkatkan suatu laju reaksi kimia untuk mencapai suatu kesetimbangan reaksi kimianya. Katalis dapat mempercepat suatu laju reaksi kimia dengan menyediakan suatu jalur reaksi alternatif yang mempunyai energi aktivasi yang lebih rendah sehingga reaksi bisa berjalan dengan cepat (Fessenden dan Fessenden, 1986). Biasanya reaksi esterfikasi menggunakan katalis asam kuat dengan mekanisme Fischer (Setiadi, 2008), tetapi mekanisme ini cenderung memiliki hasil rendemen yang kurang baik.

$$
\text { Dengan penambahan }
$$
disikloheksilkarbodiimida (DCC) dan 4$\mathrm{N}, \mathrm{N}$-dimetilaminopiridin (DMAP) pada reaksi esterifikasi menggunakan metode Steglich, memungkinkan hasil reaksi memiliki rendemen yang jauh lebih baik dibandingkan katalis asam kuat. Pada reaksi esterfikasi Steglich terdapat aktivator asam karboksilat (DCC) sehingga asam karboksilat lebih reaktif dan terdapat katalis (DMAP). Pada penelitian yang telah dilakukan oleh
Setiadi (2008), sintesis asam vanilat dengan maltosa melalui reaksi esterifikasi dengan mekanisme Steglich menghasilkan senyawa ester maltovanilat.

Senyawa ester dapat dibuat dengan mereaksikan vanilil alkohol dengan asam p-hidroksibenzoat (paraben). Turunan asam p-hidroksi benzoat merupakan senyawa yang memiliki beberapa aktivitas di antaranya sebagai antiseptik dan pengawet.

Penelitian

tentang pengembangan senyawa antimikroba telah banyak dikembangkan baik terhadap bahan dari senyawa alam ataupun senyawa sintetik. Pada penelitian ini dilakukan sintesis senyawa ester vanilil p-hidroksibenzoat dengan mereaksikan vanilil alkohol dengan asam p-hidroksibenzoat. Senyawa ester vanilil paraben (vanilil $p$-hidroksibenzoat) yang diperoleh diharapkan memiliki aktivitas antimikroba yang dapat digunakan untuk pengobatan.

\section{Metode Penelitian}

Alat dan Bahan

Alat yang digunakan adalah labu leher dua, hot plate dan stirrer, kondensor, termometer, spatula, corong pisah, ring stand, cawan petri, perangkat 
ekstraksi, autoklaf, inkubator, oven, rotary evaporator, timbangan analitik, jarum ose, pinset, jangka sorong, mikropipet (brand), laminar air flow, alumunium foil, kapas, spatel, silinder, dan alat gelas lainnya. Bahan yang digunakan dalam penelitian ini meliputi bakteri Staphylococcus aureus ATCC 25923 dan jamur Candida albicans ATCC 10231 yang diperoleh dari Laboratorium Mikrobiologi, Fakultas Kedokteran, Universitas Indonesia. Medium yang digunakan adalah medium NA (Nutrient Agar) dan medium PDA (Potato Dextrose Agar). Bahan kimia meliputi vanilin, asam p-hidroksibenzoat, etanol, aseton, tetrahidrofuran, $\mathrm{H}_{2} \mathrm{SO}_{4}$ pekat, $\mathrm{NaHCO}_{3}$ $10 \%, \mathrm{Na}_{2} \mathrm{SO}_{4}$ anhidrat, $\mathrm{NaBH}_{4}, \mathrm{CH}_{2} \mathrm{Cl}_{2}$, etil asetat, n-heksana, dan akuades.

\section{Jalannya Penelitian}

1. Reduksi vanilin dengan natrium borohidrida

Sebanyak 1,5 gram $(0,04 \mathrm{~mol})$ $\mathrm{NaBH}_{4}$ dan 3 gram $(0,0197$ mol $)$ vanilin dalam pelarut etanol dimasukkan ke dalam labu leher tiga kapasitas $250 \mathrm{~mL}$ yang dilengkapi dengan termometer, pendingin balik, dan pengaduk magnet serta penangas air. Campuran diaduk selama 40 menit pada suhu kamar. Campuran kemudian diasamkan dengan $\mathrm{HCl}$ 2,5
M sampai $\mathrm{pH} 4,5$, kemudian diekstraksi dengan $\mathrm{CH}_{2} \mathrm{Cl}_{2}$, ditambah dengan $\mathrm{Na}_{2} \mathrm{SO}_{4}$ anhidrous, disaring dan dievaporasi. Analisis senyawa hasil dilakukan dengan FTIR.

2. Sintesis vanilil $p$-hidroksibenzoat dengan katalis DCC/DMAP

Proses esterifikasi dilakukan dengan menggunakan peralatan refluks dan labu leher tiga yang ditempatkan pada waterbath dengan rasio mol reaktan $1: 4$ (vanilil alkohol dan asam p-hidroksi benzoat). Aseton sebanyak $10 \mathrm{~mL}$, DCC dan DMAP sebagai aktivator dan katalis masing-masing sebanyak $370,8 \mathrm{mg}(1,8 \mathrm{mmol})$ dan $21,99 \mathrm{mg}$ $(0,18 \mathrm{mmol})$ dimasukkan ke dalam labu leher satu. Kemudian labu leher satu tersebut dihubungkan dengan kondensor dan ditempatkan pada wadah yang sudah ada parafin. Vanilil alkohol dan asam p-hidroksi benzoat dimasukkan ke dalam labu leher satu, dimasukan juga katalis dan aktivator pada suhu $60{ }^{\circ} \mathrm{C}$. Proses ini berlangsung selama 24 jam disertai dengan pengadukan. Produk yang dihasilkan kemudian diidentifikasi.

3. Pemurnian hasil reaksi 
Setelah hasil reaksi, filtrat kemudian ditambahkan dengan larutan $\mathrm{NaHCO}_{3} \quad 10 \%$ sampai tidak terbentuk lagi $\mathrm{CO}_{2}$. Filtrat kemudian dimasukkan ke dalam corong pisah yang telah berisi kloroform, lalu dikocok. Campuran dicuci sebanyak 3 kali. Hal ini bertujuan agar ester yang terbentuk terpisah dari pengotor yang bersifat polar. Kemudian fase organik dipisahkan dari fase airnya, ditambahkan dengan $\mathrm{Na}_{2} \mathrm{SO}_{4}$, lalu disaring. Setelah disaring kemudian pelarutnya diuapkan. Untuk meningkatkan kemurnian, perlu dilakukan juga pemurnian dengan kromatografi kolom.

4. Karakterisasi dan elusidasi struktur senyawa hasil sintesis

Senyawa ester yang dihasilkan diuji kualitatif dengan KLT menggunakan pelarut pengembang etil asetat dan n-heksana. Setelah produk ester dimurnikan, dikarakterisasi dengan FTIR, LCMS, NMR, dan penentuan titik leleh. Rendemen hasil sintesis diperoleh sesuai dengan Persamaan 1.

Rendemen $=\frac{\text { Bobot hasil sintesis }}{\text { Bobot teoritis }} x 100 \%$

\section{Hasil dan Pembahasan}

Hasil Reduksi Vanilin dengan Natrium Borohidrida

Vanilin yang digunakan untuk mensintesis senyawa ester vanilil phidroksibenzoat, harus direduksi terlebih dahulu. Reduksi dilakukan pada gugus aldehida $[\mathrm{R}-\mathrm{COH}]$ menjadi gugus alkohol [R-OH]. Proses pembentukan vanilil alkohol adalah dengan cara mereduksikan vanilin menggunakan natrium borohidrida $\left(\mathrm{NaBH}_{4}\right)$, sesuai dengan reaksi pada Gambar 1.

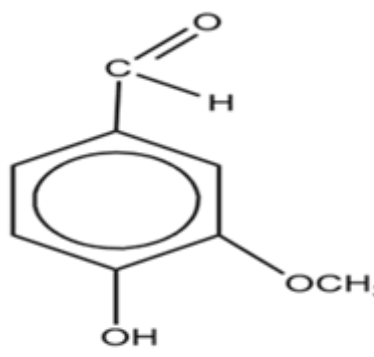

Vanilin

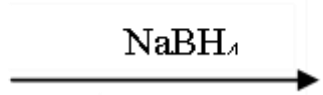

$\mathrm{H}_{2} \mathrm{O}, \mathrm{H}^{+}$

Gambar 1. Reduksi vanilin. 
Reaksi reduksi vanilin menjadi vanilil alkohol dapat dilakukan dalam air atau alkohol berair sebagai pelarut. Untuk mereduksi suatu aldehida atau keton dipilih $\mathrm{NaBH}_{4}$, karena lebih mudah penanganannya dan tidak reaktif terhadap air.

$$
\text { Pencampuran antara vanilin }
$$

dan $\mathrm{NaBH}_{4}$ menghasilkan uap panas karena penambahan $\mathrm{NaBH}_{4}$ menghasilkan panas dari dalam tempat keluar lingkungan atau bersifat eksoterm, sehingga tidak diperlukan adanya pemanasan dalam proses reduksi vanilin menjadi vanilil alkohol. Hasil reduksi kemudian diasamkan dengan penambahan $\mathrm{HCl} 2,5 \mathrm{M}$ sampai $\mathrm{pH} 4,5$. Hal ini ditandai dengan terbentuknya gumpalan putih dan larutan berwarna putih. $\mathrm{NaBH}_{4}$ bersifat basa jika mengikat ion hidroksi, penambahan $\mathrm{HCl} 2,5 \mathrm{M}$ adalah untuk penambahan atom $\mathrm{H}^{+}$ke gugus $\mathrm{O}^{-}$agar terbentuknya alkohol sekunder yang ditandai dengan adanya endapan putih dari campuran karena sudah terbentuk $\mathrm{NaCl}$ dari hasil penambahan $\mathrm{HCl}$ 2,5 M (Gambar 2).

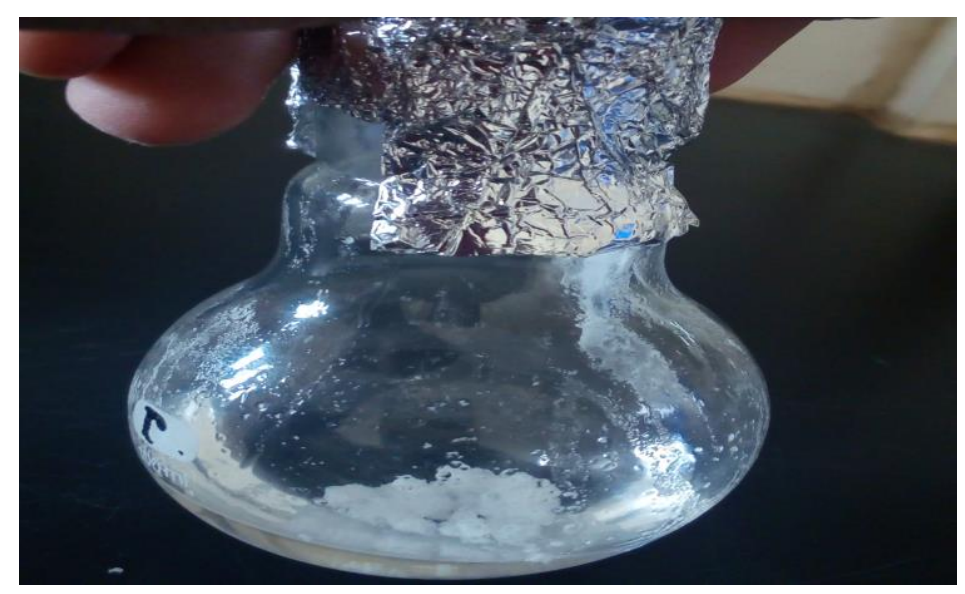

Gambar 2. Endapan putih $\mathrm{NaCl}$.

\begin{tabular}{lcrll} 
Filtrat & hasil penyaringan & \multicolumn{2}{l}{ merupakan ekstraksi cair-cair dengan } \\
kemudian & diekstraksi & untuk & prinsip pemisahan berdasarkan \\
mendapatkan senyawa polar dengan & perbedaan kepolaran dan perbedaan \\
menggunakan & pelarut & $\mathrm{CH}_{2} \mathrm{Cl}_{2}$ & bobot jenis, sehingga akan terdapat 2 \\
(diklorometana) sebanyak $10 \mathrm{~mL}$, & lapisan pada corong pisah. Sifat dari \\
ekstraksi dengan corong pisah & pelarut diklorometana adalah semipolar,
\end{tabular}


sehingga pada ekstraksi cair-cair ini senyawa yang bersifat polar akan tertarik ke bagian polar dan senyawa yang bersifat nonpolar akan tertarik ke bagian nonpolar (like disolve like). Vanilil alkohol merupakan senyawa yang bersifat polar. Lapisan paling bawah diambil dan dimasukkan ke dalam beaker glass kemudian ditambahkan dengan $\mathrm{Na}_{2} \mathrm{SO}_{4}$ anhidrat. Fungsi penambahan natrium sulfat adalah untuk mengikat molekul air yang masih terdapat pada hasil fraksi diklorometana. Proses perendaman dengan natrium sulfat dilakukan selama 30 menit kemudian dilakukan filtrasi. Hasil filtrasi ditampung ke labu bulat $100 \mathrm{~mL}$ untuk segera dievaporasi yang bertujuan untuk mendapatkan serbuk vanilil alkohol.

Serbuk vanilil alkohol diuji secara kualitatif yang bertujuan untuk melihat parameter spesifik dari senyawa yang dihasilkan. Uji pertama yaitu mengamati organoleptis meliputi bentuk, warna, dan bau. Uji kedua yaitu melihat titik leleh dari vanilil alkohol yang bertujuan untuk menentukan kemurnian dari vanilil alkohol. Uji ketiga yaitu menentukan faktor retensi (Rf) dengan metode KLT menggunakan eluen diklorometana $:$ benzena $:$ asam asetat $=$ 50 : 1 : 1 dan menggunakan plat KLT silika gel 60 F254 yang akan terfluororesensi pada panjang gelombang $254 \mathrm{~nm}$. Uji keempat yaitu menggunakan alat instrumentasi FTIR untuk membandingkan grafik puncak yang terbentuk dari vanilil alkohol dengan vanilin yang dilihat pada rentang panjang gelombang gugus karbonil aldehida yang sudah direduksikan menjadi gugus fungsi karbonil alkohol.

Pada proses KLT didapatkan hasil bahwa bercak spot dari vanilil alkohol lebih rendah dibandingkan dengan bercak spot dari vanilin yang menandai sudah hilangnya gugus aldehida dan berubah menjadi gugus alkohol. Sifat kepolaran dari gugus aldehida lebih rendah dibandingkan dengan gugus alkohol sehingga $\mathrm{Rf}$ dari vanilil alkohol lebih rendah dari vanillin, sehingga waktu retensi untuk melewati fase diam lebih lama.

Tabel 1 memperlihatkan organoleptis, nilai Rf, dan persentase rendemen vanilil alkohol yang telah berhasil direduksi. Senyawa vanilil alkohol hasil sintesis dibandingkan dengan data hasil reduksi yang dilakukan pada penelitian sebelumnya yang pernah mereduksi vanilin untuk mensintesis senyawa ester dengan bahan dasar vanilil alkohol (Budimarwanti, 2009). 
Vol. 15 No. 02 Desember 2018

Tabel 1. Karakteristik dan pengamatan hasil reaksi reduksi

\begin{tabular}{ll}
\hline Karakteristik & Hasil Pengamatan \\
\hline Bentuk & Serbuk hablur \\
Warna & Putih \\
Bau & Berbau khas \\
KLT & Rf vanilin alkohol 0,54 \\
Rendemen & $76,03 \%$ \\
\hline
\end{tabular}

Hasil dari pembacaan dengan FTIR menggunakan interval daerah serapan $650-4000 \mathrm{~cm}^{-1}$ dapat dilihat pada Tabel 2. Sampel serbuk diletakkan pada kaca yang terbuat dari zinc selenium yang dilengkapi dengan detektor (dTGS). Molekul yang menyerap sinar IR akan mengalami perubahan tingkat energi vibrasi/rotasi. Senyawa vanilil alkohol memiliki daerah serapan pada 3438,5 $\mathrm{cm}^{-1}$ yang menyatakan gugus fungsi dari alkohol dengan interval frekuensi 3500$3200 \mathrm{~cm}^{-1}$. Hasil analisis spektrum IR senyawa hasil reduksi vanilin menunjukkan tidak adanya serapan gugus karbonil aldehida. Hal ini menunjukkan bahwa gugus aldehida vanilin sudah mengalami reaksi reduksi menjadi alkohol primer. Terjadinya alkohol primer didukung adanya serapan -OH bebas (tidak ada ikatan hidrogen) di $3438,5 \mathrm{~cm}^{-1}$. Serapan $-\mathrm{OH}$ bebas ini tidak dimiliki oleh spektrum IR vanilin. Adanya alkohol primer juga didukung oleh serapan di daerah $1466,7 \mathrm{~cm}^{-1}$ yang menunjukkan gugus metilena $\mathrm{CH}_{2}$.

Tabel 2. Serapan senyawa vanillin dan vanilil alkohol dengan FTIR

\begin{tabular}{cccc}
\hline Gugus Fungsi & Kisaran Frekuensi IR $\left(\mathbf{c m}^{-1}\right)$ & Vanilin $\left(\mathbf{c m}^{-1}\right)$ & Vanilil alkohol $\left(\mathbf{c m}^{-1}\right)$ \\
\hline$-\mathrm{C}=\mathrm{O}$ aldehida & $1740-1720$ & 1661,4 & - \\
$-\mathrm{CH}$ aldehida & $2900-2800$ & 2858,5 & - \\
OH Bebas & $3650-3600$ & - & 3438,5 \\
$\mathrm{OH}$ ikatan Hidrogen & $3500-3200$ & 3149 & 3151,5 \\
$-\mathrm{OCH}_{3}$ & $2850-2810$ & 2810 & 2888,7 \\
$-\mathrm{CH}_{2-}$ & 1465 & - & 1466,7 \\
\hline
\end{tabular}

Hasil Sintesis Vanilil p-Hidroksibenzoat Penggunaan bahan pereaksi vanilil alkohol dan asam $p$ hidroksibenzoat dengan perbandingan mol 2 : 1 , bertujuan supaya senyawa asam p-hidroksibenzoat dapat 
teresterifikasi ke dalam vanilil alkohol, yaitu pada gugus $\mathrm{OH}$ primer vanilil alkohol karena halangan steriknya yang lebih rendah. Asam p-hidroksibenzoat memiliki gugus Hidroksi (-OH) pada posisi para, terdapatnya gugus hidroksi pada posisi para tidak akan menghambat terbentuknya ester dari gugus karboksilat pada asam p-hidroksibenzoat dengan alkohol primer dari vanilil alkohol karena posisi para merupakan posisi yang paling reaktif sehingga tidak akan menghambat proses esterifikasi. Adanya halangan sterik yang sedikit pada proses esterifikasi dari senyawa asam $p$ hidroksibenzoat dengan vanilil alkohol, memerlukan adanya katalis untuk mempercepat terbentuknya reaksi dan perlu adanya proses pengadukan setiap detiknya. Umumnya proses esterifikasi menggunakan katalis asam. Katalis yang bersifat asam dapat menghidrolisis vanilil alkohol, akibatnya produk ester tidak dapat diperoleh. Oleh karena itu, dalam penelitian ini esterifikasi asam $p$ hidroksibenzoat dengan vanilil alkohol tidak menggunakan katalis asam, namun menggunakan katalis DMAP dengan dibantu senyawa DCC sebagai aktivator. Dengan kombinasi kerja dari kedua senyawa tersebut, diharapkan reaksi esterifikasi dapat berlangsung dalam waktu yang relatif singkat dan diperoleh produk vanilil $p$-hidroksibenzoat secara optimal. DMAP sebagai katalis dapat dikombinasikan dengan aktivatornya DCC yang menghasilkan metode yang berguna untuk meragamkan asam karboksilat agar dapat bereaksi dengan alkohol untuk menghasilkan ester (Gambar 3).

Senyawa asam phidroksibenzoat memiliki gugus asam karboksilat. Gugus asam karboksilat mempunyai gugus $\mathrm{H}^{+}$sehingga pada senyawa DCC akan berikatan dengan $\mathrm{H}^{+}$. Ikatan $\mathrm{H}^{+}$dengan nukleofil pada DCC (karena $\mathrm{N}$ memiliki 1 pasang elektron bebas), kemudian $\mathrm{O}$ yang bermuatan negatif (nukleofil) pada asam p-hidroksi akan berikatan dengan atom $\mathrm{C}$ (elektrofil) pada DCC, dan memutus ikatan rangkap dua sehingga terjadi rotasi ikatan rangkap $\mathrm{N}$ pada $\mathrm{DCC}$, dan selanjutnya akan membentuk senyawa intermediet $\quad \mathrm{O}$-asilisourea, yang kereaktifannya serupa dengan tingkat kereaktifan senyawa anhidrida karboksilat. 
<smiles>COc1cc(OC(=O)c2ccc(O)c(C(=O)Oc3ccc(C(=O)Oc4ccc(O)cc4)cc3)c2)ccc1O</smiles>

Vanilil alkohol Asam p-hidroksibenzoat Vanilil p-hidroksibenzoat

Gambar 3. Reaksi esterifikasi dari vanilil alkohol dan asam p-hidroksi benzoat dengan katalis DCC dan DMAP.

Senyawa anhidrida asam akan mudah bereaksi dengan katalis DMAP. Adanya gugus alkohol primer berfungsi untuk menstabilkan senyawa ester yang akan terbentuk supaya tidak kembali lagi ke senyawa asam karboksilat. Setelah proses terbentukan senyawa ester telah selesai, DMAP akan terlepas kembali. Oleh karena itu pada akhir rekasi akan terbentuk ester dan DCU (disikloheksilurea).

Proses sintesis senyawa vanilil $p$ hidroksibenzoat menggunakan pelarut tetrahidrofuran. Pemilihan pelarut pada proses sintesis senyawa organik merupakan hal yang penting diperhatikan. Pelarut tetrahidrofuran memiliki titik didih rendah yaitu $65{ }^{\circ} \mathrm{C}$. Pelarut tetrahidrofuran merupakan pelarut amfiprotik yang baik digunakan untuk sintesis organik dan juga tidak akan merusak senyawa hasil sintesis. Vanilil alkohol larut dengan THF, asam phidroksibenzoat larut dengan THF, serta katalis dan aktivator yang digunakan yaitu DCC dan DMAP larut dalam THF. Waktu yang digunakan untuk mensintesis senyawa vanilil $p$ hidroksibenzoat dengan menggunakan metode esterifikasi Steglich yaitu selama 24 jam. Proses sintesis harus diaduk menggunakan refluks selama 24 jam. Setiap 6 jam, cuplikan hasil sintesis pada labu bulat diambil untuk diuji menggunakan KLT yang bertujuan untuk mengamati terbentuknya produk ester yang ditandai dengan adanya spot yang lebih tinggi dari pereaksinya. Eluen yang digunakan untuk menentukan adanya produk yang terbentuk adalah campuran yang terdiri dari 2-3 pelarut yang berbeda untuk fase gerak. Eluen yang 
digunakan yaitu $n$-heksana : etil asetat (1

: 2). Hasil Rf yang didapatkan menunjukkan $\mathrm{Rf}$ produk ester vanilil $\mathrm{p}$ hidroksibenzoat menggunakan pelarut THF, lebih besar, dengan nilai Rf 0,7. Dari hasil KLT diketahui bahwa setelah 24 jam sudah terbentuk vanilil $p$ hidroksibenzoat.

Setelah 24 jam, campuran disaring untuk menghilangkan DCU, kemudian filtratnya dibilas dengan air untuk menarik kembali DCU yang masih tertinggal pada campuran tersebut. Karena DCU merupakan pengotor atau produk samping, setelah dibilas dengan air, campuran tersebut kemudian dinetralkan dengan $\mathrm{NaHCO}_{3}$. Sebelum ditambahkan $\mathrm{NaHCO}_{3}, \mathrm{pH}$ awal campuran diukur terlebih dahulu. $\mathrm{pH}$ awal campuran ini yaitu 6 sehingga untuk mendapatkan pH $7 \mathrm{NaHCO}_{3}$ yang ditambahkan tidak terlalu banyak yaitu sekitar 20 tetes.

Setelah netral, campuran dipisahkan dengan metode ekstraksi cair-cair (fraksinasi) dengan menggunakan alat corong pisah, yang bertujuan untuk memisahkan campuran yang ada pada zat cair berdasarkan perbedaan kepolarannya. Pelarut yang digunakan untuk proses fraksinasi adalah n-heksana yang bersifat nonpolar.
Pemilihan pelarut untuk proses fraksinasi bertujuan untuk menarik senyawa yang bersifat nonpolar karena senyawa ester yang terbentuk bersifat nonpolar sehingga akan tertarik dengan pelarut nonpolar yaitu n-heksana. Pada proses fraksinasi terdapat 2 lapisan pada corong pisah setelah dikocok, 2 lapisan ini disebabkan karena adanya perbedaan bobot jenis dari kedua larutannya. Fraksi yang diambil adalah fraksi n-heksana yang terdapat pada lapisan atas di corong pisah, karena BJ dari n-heksana $(0,6548 \mathrm{~g} / \mathrm{mL})$ lebih kecil dari BJ air $(1,000 \mathrm{~g} / \mathrm{mL})$. Proses selanjutnya yaitu dilakukannya penguapan pelarut untuk didapatkan serbuk. Untuk meningkatkan kemurnian, dilakukan juga kromatografi kolom dengan menggunakan eluen nheksana : etil asetat (1:2). Kelarutan dari vanilil $p$-hidroksibenzoat yaitu larut dalam etanol, metanol, dan diklorometana, berat sampel yang didapat dari hasil sintesis menggunakan pelarut THF adalah $1223 \mathrm{mg}$ dengan persentase rendemen 55,90\%.

Karakterisasi dan Elusidasi Struktur Senyawa Hasil Sintesis

1. Uji organoleptis

Uji organoleptis bertujuan untuk melihat bentuk fisik dari produk hasil sintesis yang dihasilkan. Sampel 
ester merupakan sampel ester yang terbentuk dari sintesis metode Steglich menggunakan pelarut THF.
Organoleptis dari produk ester yang dihasilkan bisa dilihat di Tabel 3 .

Tabel 3. Perbandingan organoleptis sampel ester

\begin{tabular}{ll}
\hline Organoleptis & Sampel Ester \\
\hline Warna & Kuning kecoklatan \\
Bentuk & Serbuk kasar \\
Bau & Berbau khas \\
\hline
\end{tabular}

2. Uji kualitatif pembentukkan ester dengan uji KLT

Setelah didapatkan serbuk vanilil p-hidroksibenzoat, kemudian diuji kualitatif dengan KLT untuk melihat adanya produk ester yang terbentuk. Pelarut pengembang yang digunakan yaitu n-heksana : etil asetat (1:2).
Pengujian KLT ini dibandingkan dengan dengan senyawa pembanding vanilil alkohol dan asam phidroksibenzoat. Produk hasil sintesis bersifat lebih nonpolar sehingga bisa mendapatkan nilai Rf yang lebih tinggi yaitu Rf vanilil p-hidroksibenzoat sebesar 0,7 (Tabel 4).

Tabel 4. Nilai faktor retensi senyawa produk ester

\begin{tabular}{cccc}
\hline Sampel & Jarak Spot $(\mathbf{c m})$ & Jarak Elusi Eluen $(\mathbf{c m})$ & Nilai RF \\
\hline Sampel Ester & 3,5 & 5 & 0,7 \\
\hline
\end{tabular}

3. Penentuan jarak lebur senyawa hasil sintesis

Penentuan titik leleh bertujuan untuk melihat kemurnian suatu senyawa yang dihasilkan. Rentang kemurnian suatu senyawa melalui titik leleh yaitu $\pm 2{ }^{\circ} \mathrm{C}$. Alat yang digunakan untuk menentukan titik leleh disebut dengan melting point block dengan prinsip kerja melihat suhu melelehnya sampel padatan menjadi cairan. Struktur senyawa dari vanilil phidroksibenzoat menyerupai dengan struktur senyawa dari benzilbenzoat yang memiliki titik leleh pada suhu 154-157 ${ }^{\circ} \mathrm{C}$. Pengamatan titik leleh dari senyawa vanilil $p$-hidroksibenzoat menunjukkan terbentuknya produk 
ester yang murni karena titik lelehnya sama dengan titik leleh benzilbenzoat dengan rentang kemurnian sebesar 0 $2{ }^{\circ} \mathrm{C}$.

4. Karakterisasi senyawa dengan spektrometri infra merah

Teknik infra merah dalam analisis kualitatif mempunyai keterbatasan yang tidak dapat diabaikan. Pertama tidak adanya hubungan antara hukum Beer dan kompleksitas spektrum sehingga tumpang-tindihnya puncak-puncak. Kedua, sempitnya puncak akibat dari sinar hamburan menyebabkan pemakaian lebar slit menjadi besar. Sel yang sempit juga tidak banyak digunakan untuk mengerjakan pekerjaan praktis.

Penentuan spektrum infra merah ini bertujuan untuk menganalisis spektrum senyawa ester yang sudah terbentuk dari hasil sintesis. Spektrum infra merah senyawa vanilil phidroksibenzoat memperlihatkan gugus fungsi senyawa ester pada puncak-puncak pada bilangan gelombang hasil FTIR. Analisis gugus fungsi vanilil $p$-hidroksibenzoat melalui adanya puncak pada spektrum infra merah menunjukkan adanya gugus $\mathrm{C}=\mathrm{O}$ pada frekuensi
$1735,1 \mathrm{~cm}^{-1}$ dengan puncak yang lemah, adanya gugus $\mathrm{C}-\mathrm{O}$ pada frekuensi $1258 \mathrm{~cm}^{-1}$ dengan puncak yang tajam, adanya gugus $>\mathrm{CO}$ ester pada frekuensi $2117,1 \mathrm{~cm}^{-1}$ dengan puncak lemah, adanya gugus $\mathrm{OH}$ bebas pada frekuensi $3322,9 \mathrm{~cm}^{-1}$ dengan puncak yang lemah dan adanya posisi para untuk $\mathrm{OH}$ pada frekuensi $830 \mathrm{~cm}^{-1}$ dengan puncak yang sedang.

Tabel 5 menunjukkan perbandingan frekuensi serapan bilangan gelombang dari produk ester yang terbentuk dibandingkan dengan frekuensi dari pereaksinya. Pembacaan frekuensi bilangan gelombang spektrum infra merah diperoleh adanya gugus ester pada bilangan gelombang 2117,1; 1735,1; dan $1258,1 \mathrm{~cm}^{-1}$. Puncak pada bilangan gelombang $2117,1 \mathrm{~cm}^{-1}$ terlihat lebih jelas dibandingkan dengan bilangan gelombang 1735,1 $\mathrm{cm}^{-1}$. Gugus $\mathrm{C}=\mathrm{O}$ pada spektrum infra merah berada pada frekuensi 1735$1750 \mathrm{~cm}^{-1}$ dan C-O pada spektrum infra merah berada pada rentang frekuensi $1300-1100 \mathrm{~cm}^{-1}$. Proses esterifikasi vanilil alkohol dengan asam p-hidroksibenzoat menghasilkan senyawa ester vanilil $p$ - 
Vol. 15 No. 02 Desember 2018

hidroksibenzoat, hal ini ditandai sudah bereaksi menjadi senyawa dengan hilangnya gugus $\mathrm{OH}$ primer ester.

pada senyawa vanilil alkohol yang

Tabel 5. Identifikasi gugus fungsi spektrum FTIR pada ester vanilil p-hidroksibenzoat

\begin{tabular}{ccccc}
\hline Gugus Fungsi & $\begin{array}{c}\text { Standar } \\
\text { Frekuensi } \\
\text { IR }\left(\mathbf{c m}^{-1}\right)\end{array}$ & $\begin{array}{c}\text { Vanilil } \\
\text { Alkohol } \\
\left(\mathbf{c m}^{-1}\right)\end{array}$ & $\begin{array}{c}\text { Asam p- } \\
\text { hidroksibenzoat } \\
\left(\mathbf{c m}^{-1}\right)\end{array}$ & $\begin{array}{c}\text { Vanilil p- } \\
\text { hidroksibenzoat } \\
\left(\mathbf{c m}^{-1}\right)\end{array}$ \\
\hline $\begin{array}{c}\text { OH Bebas } \\
-\mathrm{OCH}_{3}\end{array}$ & $3650-3600$ & 3438,5 & 3345,3 & 3322,9 \\
$\begin{array}{c}\text { C-H tidak } \\
\text { Berfungsional }\end{array}$ & $2850-2810$ & 2888,7 & - & 2851,4 \\
OH Ikatan Hidrogen & $3500-3200$ & 2965,1 & - & 2927,8 \\
Posisi Para (OH) & $800-850$ & 3151,5 & - & - \\
$>$ CO Ester & $2000-2300$ & - & 850 & 830 \\
C=O & $1750-1730$ & - & - & 2117,1 \\
C-O & $1300-1000$ & - & - & 1735,1 \\
OH Karboksilat & $3400-2400$ & - & - & 1258,1 \\
$-\mathrm{CH}_{2-}$ & $1465-1458$ & 1466,7 & - & - \\
\hline
\end{tabular}

5. Karakterisasi senyawa hasil sintesis dengan MS

Elusidasi struktur dengan LCMS memberikan hasil yang belum dapat mengkonfirmasi bobot molekul produk hasil sintesis yang seharusnya sekitar 272. Bobot molekul yang mendekati didapat pada kisaran 259260. Hal ini disebabkan kemungkinan kurang stabilnya produk senyawa hasil sintesis selama analisis. Pada hasil analisis juga menunjukkan masih adanya pengotor produk samping yaitu DCU dan ditunjukkan adanya bobot molekul DCU sebesar 225,30 $(\mathrm{M}+\mathrm{H})$.
6. Karakterisasi senyawa hasil sintesis dengan spektroskopi resonansi magnet inti $\left({ }^{1} \mathrm{H}-\mathrm{NMR}\right)$

Elusidasi struktur

menggunakan spektroskopi ${ }^{1} \mathrm{H}-\mathrm{NMR}$ menunjukkan hasil sebagai berikut: pada $\delta 3,5$ (singlet, $3 \mathrm{H}$ ) dari $-\mathrm{OCH}_{3}$; pada $\delta 3,9$ (singlet, $2 \mathrm{H}$ ) dari $-\mathrm{OCH}_{2}$; pada $\delta 5,5$ (singlet, $1 \mathrm{H}$ ) dari $-\mathrm{OH}$; pada $\delta 7,4$ (doublet-doublet, $2 \mathrm{H}$ ) dan $\delta 7,5$ (doublet-doublet, $2 \mathrm{H}$ ) dari $\mathrm{Ar}-\mathrm{CH}=$; pada $\delta 6,8$ (triplet, $1 \mathrm{H}$ ); $\delta 7,45$ (triplet, $1 \mathrm{H}) ; \delta 6,9$ (triplet, $1 \mathrm{H}$ ) dari gugus aromatis.

7. Uji aktivitas terhadap Pseudomonas aeruginosa, Staphylococcus aureus, dan Candida albicans 
Metode yang dilakukan pada uji aktivitas ini menggunakan metode difusi agar, karena metoda ini paling sering digunakan untuk menentukan aktivitas antimikroba. Prinsip kerjanya adalah dengan mengamati daerah yang bening, yang mengindikasikan adanya hambatan pertumbuhan mikroorganisme oleh antimikroba pada permukaan media agar (Jawets et al., 1995) menggunakan kertas cakram berdiameter $6 \mathrm{~mm}$ dan mikroorganisme yang akan diuji adalah Pseudomonas aeruginosa, Staphylococcus aureus, dan Candida albicans. Pengujian ini bertujuan untuk melihat kemampuan vanilil $p$ hidroksibenzoat dalam menghambat pertumbuhan Pseudomonas aeruginosa, Staphylococcus aureus, dan Candida albicans yang dilihat dari zona bening yang ditimbulkan. Ukuran zona hambatan dapat dipengaruhi oleh kepadatan media biakan, kecepatan difusi antimikroba, konsentrasi antimikroba pada cakram filter, sensitivitas organisme terhadap antimikroba, dan interaksi antimikroba terhadap media. Suatu zat yang mempunyai efek samping signifikan tidak boleh digunakan.
Konsentrasi yang digunakan pada uji aktivitas antimikroba adalah 200,400 , dan 600 ppm untuk produk vanilil p-hidroksibenzoat; 200 ppm untuk DCU; 200 ppm untuk vanilil alkohol; dan 10 ppm untuk kontrol positif kloramfenikol (untuk Pseudomonas aeruginosa dan Staphylococcus aureus); dan 10 ppm untuk kontrol positif ketokonazol (untuk Candida albicans). Hasil pengukuran diameter daerah hambat terhadap Pseudomonas aeruginosa, Staphylococcus aureus, dan Candida albicans dapat dilihat pada Tabel 6 .

Hasil pada Tabel 6 menunjukkan bahwa vanilil alkohol maupun senyawa hasil sintesis (vanilil phidroksibenzoat) mampu memberikan aktivitas dan membentuk zona bening terhadap Staphylococcus aureus. DCU tidak memiliki aktivitas antimikroba. Uji pada Candida albicans menunjukkan bahwa senyawa hasil sintesis tidak memiliki aktivitas sebagai antijamur.

Menurut Davis dan Stout (1971), kriteria kekuatan daya antibakteri adalah sebagai berikut: diameter zona hambat $5 \mathrm{~mm}$ atau kurang dikategorikan lemah, zona hambat 5$10 \mathrm{~mm}$ dikategorikan sedang, zona 
Vol. 15 No. 02 Desember 2018

hambat $10-20 \mathrm{~mm}$ dikategorikan kuat dan zona hambat $20 \mathrm{~mm}$ atau lebih dikategorikan sangat kuat. Berdasarkan kriteria tersebut, maka daya antibakteri senyawa vanilil $p$ hidroksibenzoat pada bakteri staphylococcus aureus pada konsentrasi produk 200 dan 400 ppm termasuk lemah, sedangkan pada konsentrasi 600 ppm termasuk sedang. Uji aktivitas terhadap
Pseudomonas aeroginosa pada konsentrasi produk 200 dan 400 ppm termasuk sedang dan pada konsentrasi 600 ppm termasuk kuat. Dengan demikian, diketahui bahwa konsentrasi produk vanilil $p$ hidroksibenzoat pada konsentrasi 600 ppm merupakan konsentrasi efektif untuk menghambat bakteri Staphylococcus aureus maupun Pseudomonas aeroginosa.

Tabel 6. Uji aktivitas antimikroba senyawa p-hidroksibenzoat terhadap Pseudomonas aeruginosa, Staphylococcus aureus, dan Candida albicans

\begin{tabular}{|c|c|c|c|c|c|}
\hline \multirow{2}{*}{ Jenis mikroba } & \multirow{2}{*}{ Senyawa Uji } & \multicolumn{3}{|c|}{ Pertumbuhan Mikroba } & \multirow{2}{*}{ Rata-rata $(\mathrm{mm})$} \\
\hline & & 1 & 2 & 3 & \\
\hline Pseudomonas & Va & + & + & + & 10,10 \\
\hline \multirow[t]{5}{*}{ aeroginosa } & P2 & + & + & + & 5,20 \\
\hline & P4 & + & + & + & 5,70 \\
\hline & P6 & + & + & + & 10,10 \\
\hline & $\mathrm{D}$ & - & - & - & 0 \\
\hline & K & + & + & + & 13,30 \\
\hline Staphylococcus & Va & + & + & + & 4,30 \\
\hline \multirow[t]{5}{*}{ aureus } & P2 & + & + & + & 4,20 \\
\hline & P4 & + & + & + & 4,60 \\
\hline & P6 & + & + & + & 5,13 \\
\hline & $\mathrm{D}$ & - & - & - & 0 \\
\hline & $\mathrm{K}$ & + & + & + & 6,28 \\
\hline \multirow[t]{6}{*}{ Candida albicans } & $\mathrm{Va}$ & - & - & - & 0 \\
\hline & P2 & - & - & - & 0 \\
\hline & P4 & - & - & - & 0 \\
\hline & P6 & - & - & - & 0 \\
\hline & $\mathrm{D}$ & - & - & - & 0 \\
\hline & $K$ & + & + & + & 13,00 \\
\hline
\end{tabular}




\section{Kesimpulan}

Dari penelitian yang telah dilakukan dapat diambil kesimpulan bahwa senyawa hasil reduksi dengan $\mathrm{NaBH}_{4}$ telah terkonfirmasi vanilil alkohol melalui spektrum infra merah pada bilangan gelombang $\mathrm{OH}$ bebas 3438,5 dan $1466,7 \mathrm{~cm}^{-1}$ yang menunjukkan gugus metilen $\mathrm{CH}_{2}$ serta didapatkan rendemen sebesar $76,03 \%$. Hasil sintesis esterifikasi metode Steglich antara vanilil alkohol dan asam p-hidroksibenzoat dengan perbandingan molar $2: 1$ dalam THF, diaduk dengan pengaduk magnetik menggunakan refluks suhu $65{ }^{\circ} \mathrm{C}$ selama 24 jam menghasilkan senyawa berbentuk serbuk berwarna kuning, mempunyai titik lebur $154-157{ }^{\circ} \mathrm{C}$, dengan persentase rendemen sebesar $55,9 \%$, dan dari hasil karakterisasi dengan spektrometer infra merah dan spektroskopi resonansi magnet inti menunjukkan bahwa senyawa tersebut adalah vanilil $\mathrm{p}$-hidroksibenzoat. Daya antimikroba senyawa vanilil $p$ hidroksibenzoat pada bakteri Staphylococcus aureus pada konsentrasi produk 200 dan 400 ppm termasuk lemah, sedangkan pada konsentrasi 600 ppm termasuk sedang. Uji aktivitas terhadap Pseudomonas aeroginosa pada konsentrasi produk 200 dan 400 ppm termasuk sedang dan pada konsentrasi 600 ppm termasuk kuat. Senyawa hasil sintesis tidak memiliki aktivitas sebagai antijamur.

\section{Ucapan Terima Kasih}

Tim peneliti mengucapkan terima kasih atas pendanaan penelitian ini melalui Kemenristek Dikti dan Lemlit Uhamka.

\section{Daftar Pustaka}

Boonchird, C. and Flegel, T.W. 1982. In vitro antifungal activity of eugenol and vanillin against Candida albicans and Cryptococcus neoformans. Canadian Journal of Microbiology, 28(11):1235- 1241.

Budimarwanti, C. 2009. Sintesis senyawa 4-hidroksi-5-dimetilaminometil-3metoksibenzil alkohol dengan bahan dasar vanilin melalui reaksi Mannich. Skripsi. Jurusan Pendidikan Kimia, FMIPA, Universitas Negeri Yogyakarta.

Davis, W.W. and Stout, T.R. 1971. Disc plate method of microbiological antibiotic assay. Applied microbiology, 22(4):659-665.

Winarto, D. 2013. Sintesis vanilil sinamat dari vanilil alkohol dan asam sinamat melalui reaksi esterifikasi Fischer. Skripsi. Jurusan Kimia, FMIPA, Universitas Negeri Yogyakarta.

Fessenden, R.J. dan Fessenden, J.S. 1986. Kimia Organik. Jilid 2. Jakarta: Erlangga. 
Fitzgerald, D.J., Stratford, M., Gasson, M.J., Ueckert, J., Bos, A., and Narbad, A. 2004. Mode of antimicrobial action of vanillin against Escherichia coli, Lactobacillus plantarum, and Listeria innocua. Journal of Applied Microbiology. 97:104-113.

Jawetz, Melnick, dan Adelberg's. 2005. Mikrobiologi Kedokteran. Jakarta: Salemba Medika.

Kumar, R., Sharma, P.K., and Mishra, P.S. 2012. A review on the vanillin derivatives showing various biological activities. International Journal of PharmTech Research, 4(1):266-279.

Oliveira, C.B., Meurer, Y.S., Oliveira, M.G., Medeiros, W.M., Silva, F.O., Brito, A.C., Pontes, Dde.L., Andrade-Neto, V.F. 2014. Comparative study on the antioxidant and anti-toxoplasma activities of vanillin and its resorcinarene derivative. Molecules, 19(5):5898-5912.

Rakchoy, S., Suppakul, P., and Jinkarn, T. 2009. Antimicrobial effects of vanillin coated solution for coating paperboard intended for packaging bakery products. Asian Journal of Food and Agro-Industry, 2(04):189196.

Setiadi, M.I. 2008. Sintesis maltovanilat melalui mekanisme Steglich menggunakan pelarut aseton. Skripsi. Jurusan Kimia, FMIPA, Universitas Indonesia.

WHO. 2016. General briefs UN on antimicrobial resistance. http://www.who.int/dg/speeches/ 2016/antimicrobial-resistanceun/en/. Data diakses pada 23 Desember 2017. 